\title{
Circularly polarized antenna array based on hybrid couplers for 5 G devices
}

\author{
Tan Minh Cao', Thao Hoang Thi Phuong ${ }^{2}$, Thi Duyen Bui ${ }^{3}$ \\ ${ }^{1}$ Department of Instrument and Industrial Informatics, Hanoi University of Science \& Technology, Hanoi, Vietnam \\ ${ }^{2}$ Faculty of Electronics and Telecommunications, Electric Power University, Hanoi, Vietnam \\ ${ }^{3}$ Faculty of Control and Automation, Electric Power University, Hanoi, Vietnam
}

\begin{tabular}{l}
\hline Article Info \\
\hline Article history: \\
Received Nov 13, 2020 \\
Revised Mar 21, 2021 \\
Accepted Apr 9, 2021 \\
\hline Keywords: \\
5G \\
Antenna array \\
Beam steering antenna \\
Butler matrix \\
Circularly polarized \\
Hybrid coupler \\
Printed dipole
\end{tabular}

\begin{abstract}
This paper depicts a wideband circularly polarized (CP) antenna for 5G devices. The antenna array has a 3D structure including four simple printed dipole elements with directional radiations, high gain, and high efficiency. It achieves a CP by using the sequential rotation (SR) feeding based on $90^{\circ}$ $3 \mathrm{~dB}$ hybrid couplers in the proposed feeding network. The antenna array bandwidth is wide, $26.7 \%$, with an operating frequency band from $3.35 \mathrm{GHz}$ to $4.35 \mathrm{GHz}$. The antenna achieves a high peak gain of $10.73 \mathrm{dBi}$ and high efficiency of $93.75 \%$. Besides, the antenna gain is stable over the operating bandwidth (BW). At the centre operating frequency of $3.75 \mathrm{GHz}$, the angle of circular polarization is $51^{\circ}$. The antenna is designed and fabricated on the Rogers 4003 C substrate. The measured S11 is well matching with the simulation results. With the above characteristics, the proposed antenna can be a suitable candidate for $5 \mathrm{G}$ devices.
\end{abstract}

This is an open access article under the $\underline{C C B Y-S A}$ license.

\section{Corresponding Author:}

Thi Duyen Bui

Faculty of Control and Automation

Electric Power University

235 Hoang Quoc Viet Street, Hanoi, Vietnam

Email: duyenbt@epu.edu.vn

\section{INTRODUCTION}

Circularly polarized (CP) microstrip antennas have been used widely in many communication systems, including 5G mobile communication, because of their advantages over linearly-polarized antennas in reducing energy loss, multipath effect, and Faraday rotation effect [1]. Also, 5G operating in both spectrums, including lower frequencies, frequency range (FR1) $(4.1 \mathrm{GHz}-7.125 \mathrm{GHz}$ ), and higher frequencies, FR2 $(24.25 \mathrm{GHz}-52.6 \mathrm{GHz})$, have attracted much attention [1]. There have been several researches about CP antennas working at FR1 using several structures such as single-feed [2]-[12] or multiple-feeds [13]-[17]. Using single-feed structures to achieve a CP antenna is the simplest technique, but it has a limitation of narrow bandwidth. Meanwhile, multiple-feeds structures such as antenna arrays can give not only wide bandwidth but also high gain. These CP antenna arrays have obtained significant achievements. Still, higher gain, wider bandwidth, simpler structure requirements for FR1 bands have been a challenge in designing $\mathrm{CP}$ antenna arrays.

This paper proposes a CP antenna array that consists of four dipole elements. Rogers $4003 \mathrm{C}$ substrate is chosen to design the antenna because of low weight, low loss, and high hardness. The SR technique is applied for feeding network design using $90^{\circ}$ phase-shifters and quasi-equal-amplitude to obtain the wideband CP antenna. Two CP modes of the antenna are obtained by changing the feeding point PINdiodes element to avoid the loss and non-linear effect. The antenna achieves a CP with a degree of $51^{\circ}$, a 
high gain of $10.73 \mathrm{dBi}$, and a wide bandwidth of $26.7 \%$. The rest of this paper is organized is being as. Section 2 presents the design of the $5 \mathrm{G} \mathrm{CP}$ antenna as well as its simulated and measured results. The conclusion of the paper is in section 3.

\section{5G CIRCULARLY POLARIZED ANTENNA DESIGN}

This section presents the design of the $5 \mathrm{G} \mathrm{CP}$ antenna including the antenna element, the antenna array, and the feeding network in subsection 2.1,2.2, and 2.3 respectively. The latest describes the simulated and measured results of the proposed antenna as well as the discussion and the comparison between the archived results and the publications.

\subsection{Printed dipole antenna element}

The 5G printed dipole element with "J"-Balun is proposed in Figure 1(a) according to the theory in [17]-[22] but high gain and directional pattern. Thanks to achieving high efficiency, the dipole antennas are often chosen to design CP antennas. The antenna element is designed on Rogers $4003 \mathrm{C}$ substrate with a dielectric constant of 3.55 and a height of $0.813 \mathrm{~mm}$. On the one side of the substrate, the antenna includes a radiator with two arms and a ground for obtaining directional radiation and high antenna gain. On the other side, a "J" Balun is integrated into the feeding to ensure electricity balancing for two arms. Figure 1(b) illustrates the equivalent circuit of J-Balun for impedance studying. The radiator and Balun's detail dimensions are calculated similarly to the steps in [8]. The perfect matching is achieved when $L_{b}=L_{a b}=\lambda / 4$. The antenna is designed for the center frequency of $3.75 \mathrm{GHz}$. The parameters of the proposed antenna are calculated, optimized by CST software, and shown in Table 1. The antenna element prototype is presented in Figure 1(c).

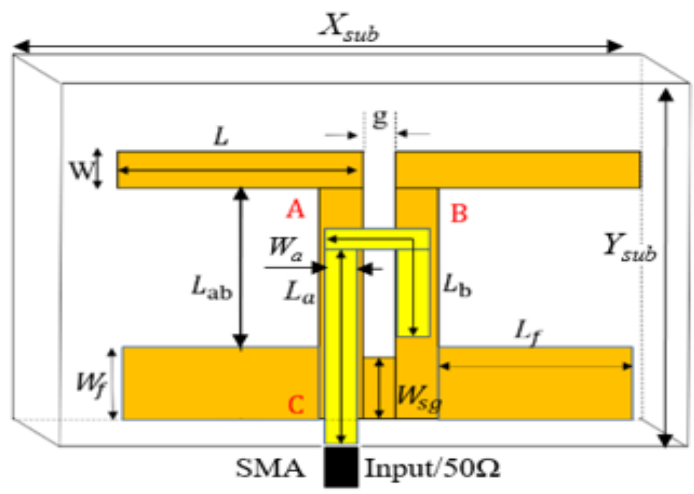

(a)

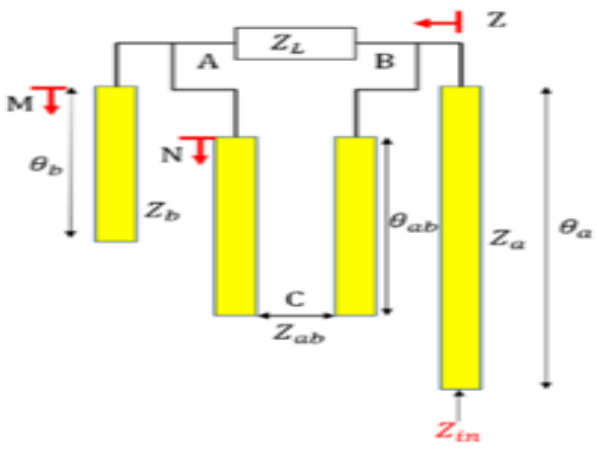

(b)

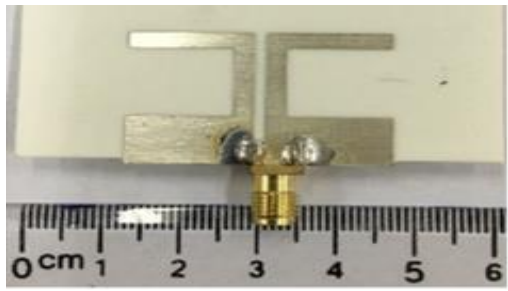

(c)

Figure 1. The printed dipole element with "J"-Balun propose, (a) The structure of printed dipole antenna,

(b) The equivalent of the "J" Balun, (c) Prototyped

Table 1. Parameters of the printed dipole with integrated "J" Balun

\begin{tabular}{cccccc}
\hline Parameters & Values $(\mathrm{mm})$ & Parameters & Values $(\mathrm{mm})$ & Parameters & Values $(\mathrm{mm})$ \\
\hline$L$ & 15.5 & $L_{b}$ & 12 & $W_{s g}$ & 2.5 \\
$L_{f}$ & 14.5 & $W$ & 2.5 & $W_{a}$ & 1.85 \\
$L_{a b}$ & $20-8$ & $W_{f}$ & 8 & $X_{\text {sub }}$ & 40 \\
$L_{a}$ & 12.92 & $g$ & 0.9 & $Y_{\text {sub }}$ & 60 \\
\hline
\end{tabular}


Figure 2 shows the $\mathrm{S} 11$ simulation results of the dipole antenna. The Figure shows that the antenna bandwidth is from $3.6 \mathrm{GHz}$ to $4 \mathrm{GHz}$ (at $\mathrm{S}_{11}<-10 \mathrm{~dB}$ ), and the simulation reflection coefficient $\mathrm{S}_{11}$ is $-45 \mathrm{~dB}$ at $3.75 \mathrm{GHz}$. Figure 3(a) presents the 3D radiation pattern of the antenna element and Figure 3(b) plots Eplane and H-plane of the radiation pattern. The printed dipole antenna achieves a peak gain of $6.478 \mathrm{dBi}$, an angular width $(-3 \mathrm{~dB})$ of $129.30^{\circ}$, and total radiation efficiency of $96.63 \%$.

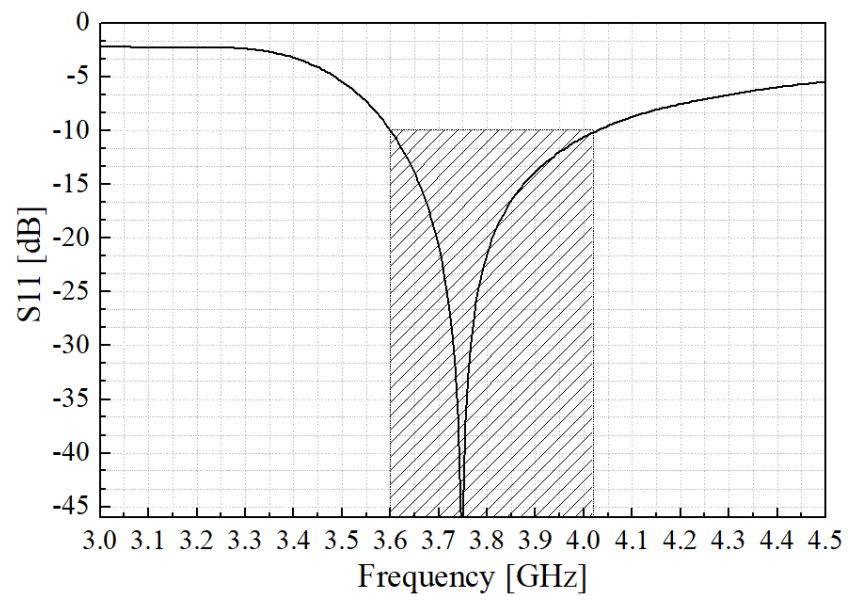

Figure 2. The simulated reflection coefficients of printed dipole antenna

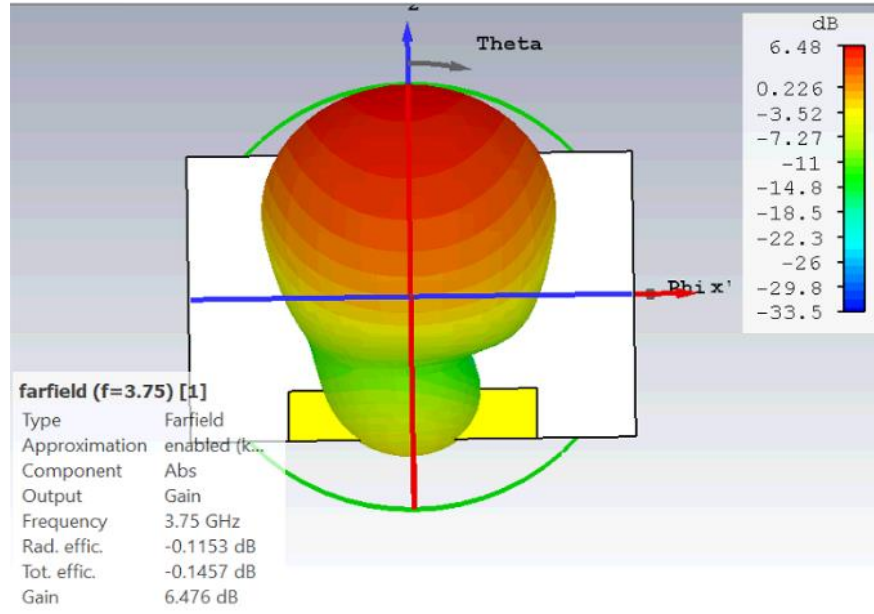

(a)

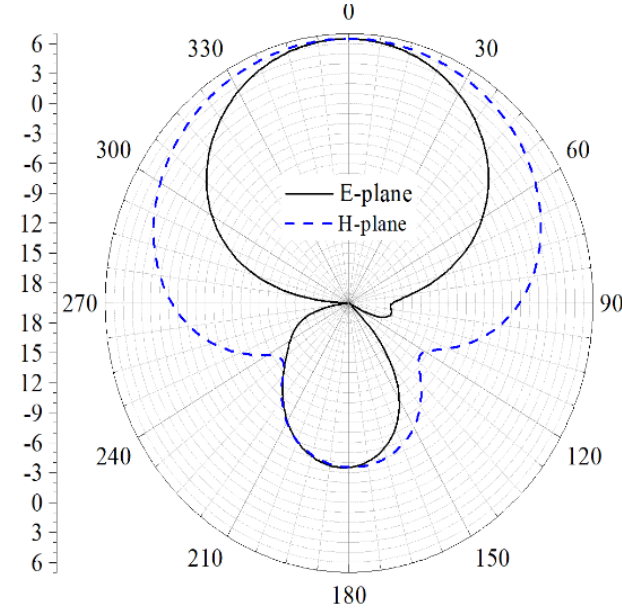

(b)

Figure 3. These figures are, (a) 3D radiation pattern of the proposed dipole element at $3.75 \mathrm{GHz}$,

(b) Radiation pattern of the proposed dipole element at $3.75 \mathrm{GHz}$ in E-plane and H-plane

\subsection{Dipole antenna array}

$\mathrm{CP}$ antennas can be achieved by using single-feed or multiple-feeds structures as mentioned in section 1. Several techniques have been reported in recent decades such as dual-feed, mutual coupling and reactive loading, stacked, aperture coupled, and sequentially rotated [23]. The CP antenna arrays that use sequentially rotated feed network generate wideband, high gain, and CP radiation from a linear polarization [5], [14], [16], [24]-[25].

Figure 4(a) shows the structure of the $\mathrm{CP}$ antenna array with a total dimension of $80 \times 80 \times 40 \mathrm{~mm}^{3}$. The antenna array consists of four above antenna elements, and the proposed feeding network presented in the next section (subsection 2.3). Two neighboring dipole elements are perpendicular, and all four elements are perpendicular to the feeding network. This configuration has the advantage of low mutual coupling between these elements in the antenna array. The antenna obtains a wideband CP by applying the SR feeding technique thanks to the feeding network. The excited phases feeding ports $2,3,4,5$ correspondings to four dipoles $2,3,4,5$ are arranged $0^{\circ}, 90^{\circ}, 180^{\circ}$, and $270^{\circ}$ as shown in Table 2. 
Table 2. Excited phases of antenna elements

\begin{tabular}{cccc}
\hline Dipole 1 (Port 2) & Dipole 2 (Port 3) & Dipole 3 (Port 4) & Dipole 4 (Port 5) \\
\hline $0^{0}$ & $90^{\circ}$ & $180^{\circ}$ & $270^{\circ}$
\end{tabular}

\subsection{Feeding network design}

The feeding network is illustrated in Figure 4(b), and the desired phase difference between adjacent feeding ports presented in Table 2 . It utilizes two $90^{\circ}-3 \mathrm{~dB}$ hybrid couplers and a $100 \Omega$ quarter-wavelength transmission lines to create $90^{\circ}$ and $180^{\circ}$ phase shifts, respectively, and $70.7 \Omega$ quarter-wavelength transmission lines for feeding and matching impedance between the elements.

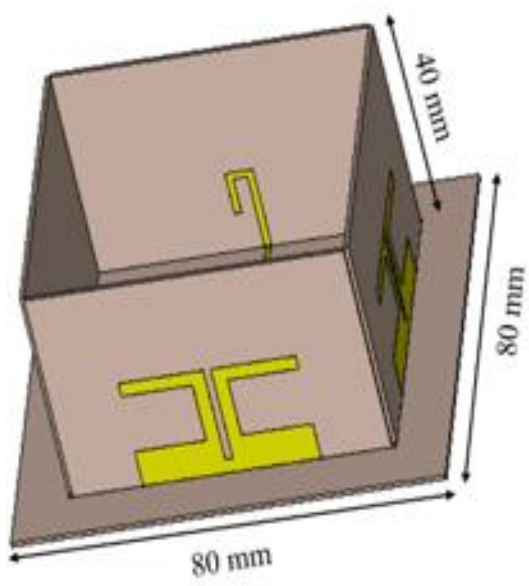

(a)

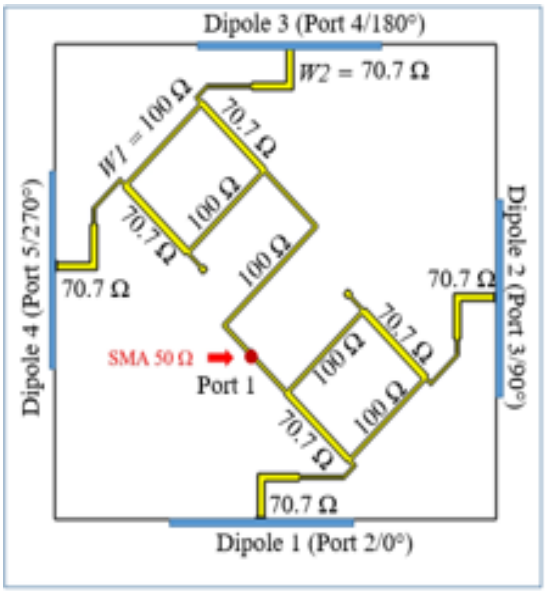

(b)

Figure 4. These figures are, (a) Structure of the CP antenna array, (b) The proposed feeding network

The $90^{\circ}-3 \mathrm{~dB}$ hybrid coupler (HC) in the proposed feeding network is used for spliting power and changing phases [11]. The $\mathrm{HC}$ is designed form on a conventional microstrip hybrid with four ports, as depicted in Figure 5. The operation principle of the $\mathrm{HC}$ in Figure 5 is depicted is being as. The input power at port 1 is divided into two equal parts to port 3 and port 4 with a 90 -degree phase change between two outputs, and it is not transmitted to port 5. S parameter of the HC is presented in (1).

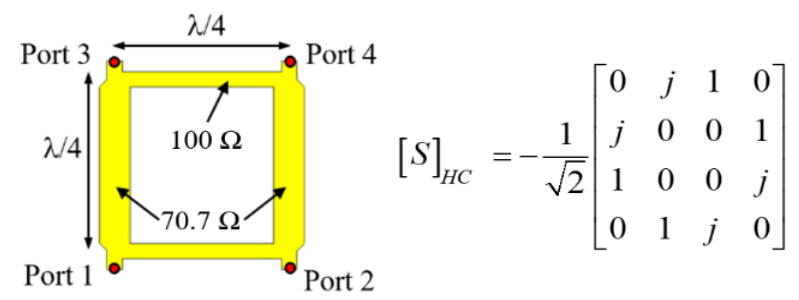

Figure 5. Structure of hybrid coupler

Figure 6 presents the S parameters and the phase changes between the two output ports of the HC in Figure 5. Figure 6(a) shows that the power at port 1 is divided into port 3 and port 4 while it is not transmitted to port 2 in operating bandwidth. It can be seen in Figure 6(b) that the phase difference tween port 3 and port 4 is $90^{\circ}$ at the center frequency of $3.75 \mathrm{GHz}$. The $3 \mathrm{~dB} \mathrm{BW}$ of the $\mathrm{HC}$ at $-10 \mathrm{~dB}$ is from $3 \mathrm{GHz}$ to $4.5 \mathrm{GHz}$. These two HCs are integrated into the feeding network.

The input power with 50-ohm impedance at port 1as shown in Figure 4(b) is splited to feed to four elements of the array. The dipole element feed impedance must be matched with feeding lines. The length of the microstrip line from the feeding point (port 1) to port 3 (dipole 2) longer than to port 2 (dipole 1) a quarter-wavelength for obtaining a 90-degree phase delay tween port 2 and port 3 . This is similar to the pair of dipole 3 (port 4)/dipole 2 (port 3) and dipole 4 (port 5)/dipole 3 (port 4). The width of the quarter-wave 
lines is calculated to ensure impedance matching between $50 \Omega$ inputs of the dipole elements and $100 \Omega$ lines (width of W1) as well as between the input of subminiature version A (SMA) connector and $100 \Omega$ lines. The impedance of the lines to match $50 \Omega$ input dipoles and $100 \Omega$ lines are $70.7 \Omega$ with the width of W2. The value of $W 1$ and $W 2$ are calculated, then optimized by central standard time (CST) and presented in Table 3.

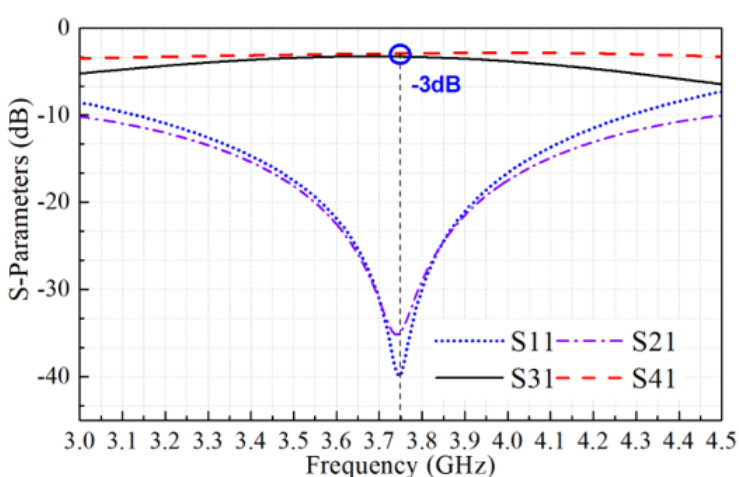

(a)

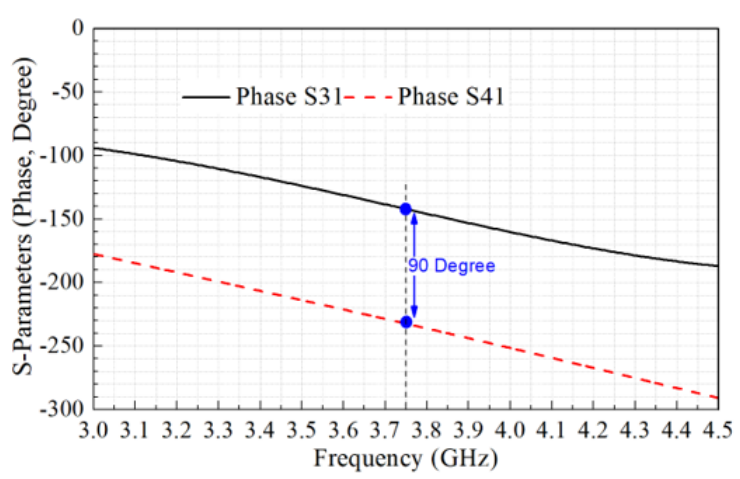

(b)

Figure 6. These figures are, (a) The phase change of the output ports, (b) The simulated S parameter

Table 3. Dimension parameters of the lines in the feeding network

\begin{tabular}{cccc}
\hline Parameters & Values $(\mathrm{mm})$ & Parameters & Values $(\mathrm{mm})$ \\
\hline W1 & 0.423 & W2 & 0.95 \\
\hline
\end{tabular}

Figure 7 depicts the simulated S-parameters of the feeding network, including amplitude and phase when exciting port 1. The Figure 7(a) that antenna bandwidth is about $1 \mathrm{GHz}(3.27 \mathrm{GHz}-4.36 \mathrm{GHz})$. The arguments of S21, S31, S41, S51 are approximately $-6 \mathrm{~dB}$ at $3.6 \mathrm{GHz}-4.0 \mathrm{GHz}$ band. It means that the power entering port 1 is equally divided into the rest four ports with low loss. Therefore, the antenna array obtains the $\mathrm{CP}$ at the band of $3.65 \mathrm{GHz}-3.93 \mathrm{GHz}$. The minimum Axial ratio (AR) of the antenna is below $2.5 \mathrm{~dB}$ at 3.6 GHz-4.0 GHz. It can be enhanced when the amplitude of excitation at all antenna element ports are the same. According to Figure 7(b), the phase delay between two inputs of dipole 2/dipole 1, dipole 3/dipole 2, and dipole 4/dipole 3 is approximately $90^{\circ}$. This phase-difference is maintained at the band of $3.6 \mathrm{GHz}-3.93$ $\mathrm{GHz}$. It explains why the $\mathrm{CP}$ antenna array has the $\mathrm{CP}$ at this band.
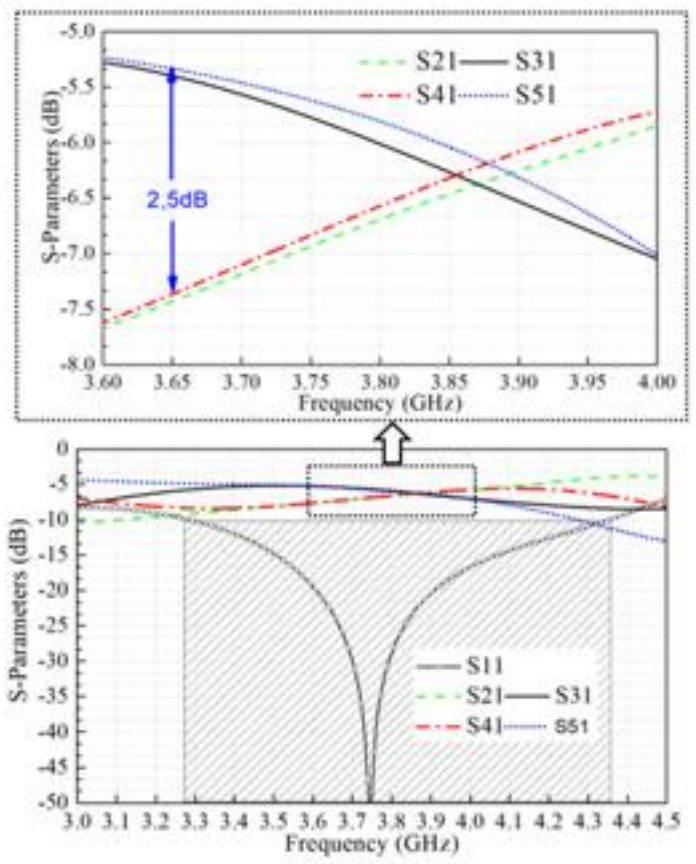

(a)

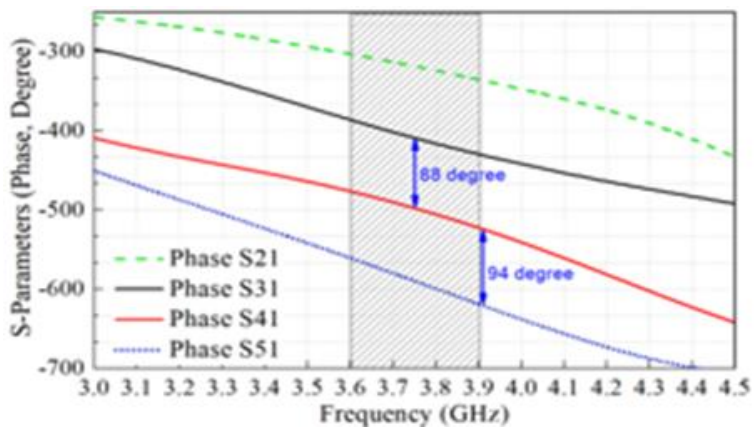

(b)

Figure 7. Simulation results of array feeding network (FN), (a) Amplitude delivery created by the FN, 


\subsection{Results and discussion}

(b) Phase delivery created by the FN

The CP antenna array is designed and fabricated on the Rogers $4003 \mathrm{C}$ substrate with the feeding network and four dipole elements as presented above. Figure 8 shows the $\mathrm{CP}$ antenna array prototype with a total dimension of $80 \times 80 \times 40 \mathrm{~mm}^{3}$. Figure 9 shows the antenna reflection coefficient. The antenna array bandwidth is increased by $16 \%$ compared to single dipole antenna bandwidth. The CP antenna array has CP from $3.65 \mathrm{GHz}$ to $3.93 \mathrm{GHz}$. The measured S11 reflection coefficient is well matching with the simulation results.

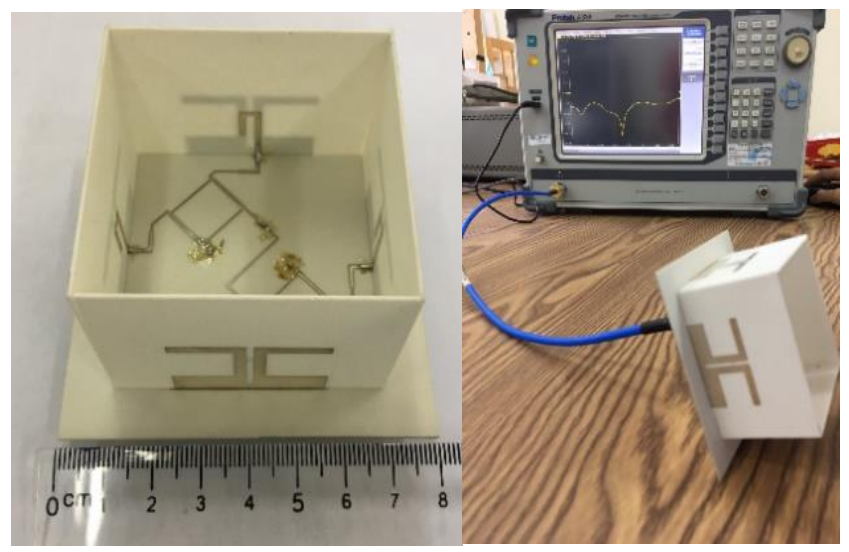

Figure 8. CP antenna prototype

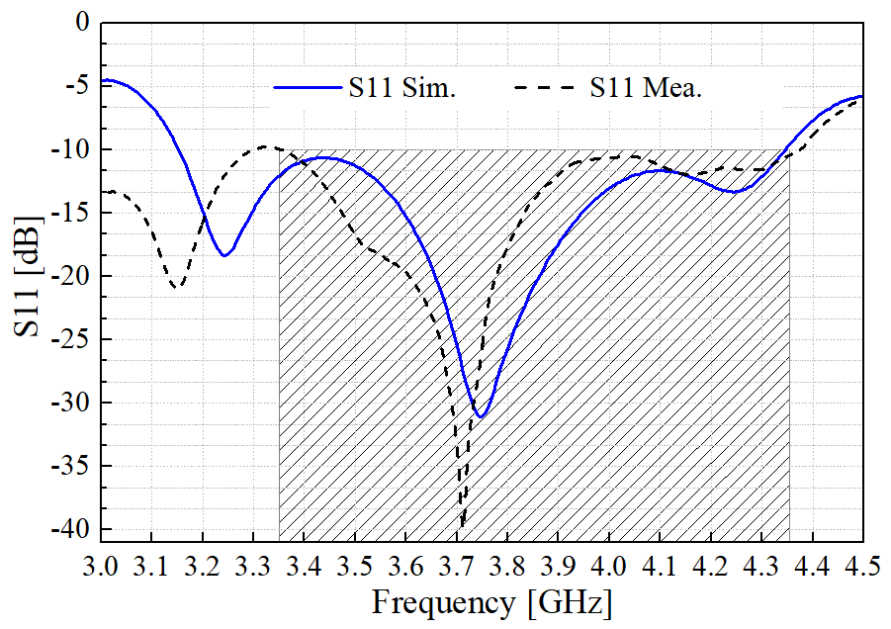

Figure 9. Simulated and measured S11

Figure 10 plots the simulated radiation pattern of our CP antenna and AR in H-plane and E-plane of the $\mathrm{CP}$ antenna array at $3.75 \mathrm{GHz}$. The Figure shows the antenna has a wide $\mathrm{CP}$ angle of $51^{\circ}$ at $3.75 \mathrm{GHz}$. Figure 11 depicts the simulated $\mathrm{AR}$ and gain of the $\mathrm{CP}$ antenna array vias frequency. The array (AR) is less than $3 \mathrm{~dB}$ in the band of $3.6 \mathrm{GHz}-3.9 \mathrm{GHz}(7.5 \%)$. It means that the proposed $\mathrm{CP}$ antenna array has high $\mathrm{CP}$ bandwidth of $250 \mathrm{MHz}$. This band's peak gain is more than $10.66 \mathrm{dBi}$ with a maximum value of $10.73 \mathrm{dBi}$ at $3.75 \mathrm{GHz}$. The total radiation efficiency is up to $93.75 \%$. At $3.75 \mathrm{GHz}$, the beam-width of circular polarization is $51^{\circ}$. Table 4 summarizes the results of several circular polarization antennas [5], [6], [16], [17] which have a wide bandwidth, a circular polarization, and a 3D structure. Our proposed design has a higher gain at the microwave frequency ranges than in [5], [6], [16], [17]. The proposed design has wider bandwidth and wider bandwidth of CP compared to [6], [16]. However, the total dimension of antennas in [16], is smaller than our antenna dimension. The smallest bandwidth antenna in [6] (BW=100 MHz) has the smallest size $(0.32 \times 0.32 \times 0.12)$. It is depict that the more broadband antenna is, the bigger the antenna dimension is. The very high gain, $\mathrm{CP}$, wideband, and low-profile are advantages of our proposed antenna. This antenna is 
easy to be integrated into the $5 \mathrm{G}$ system.

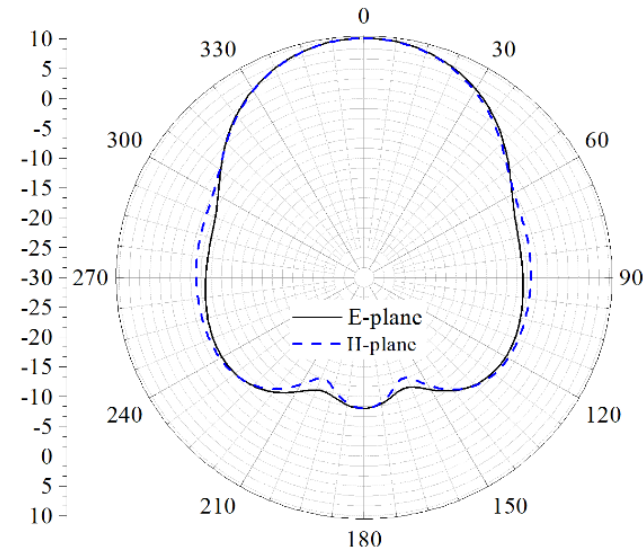

(a)

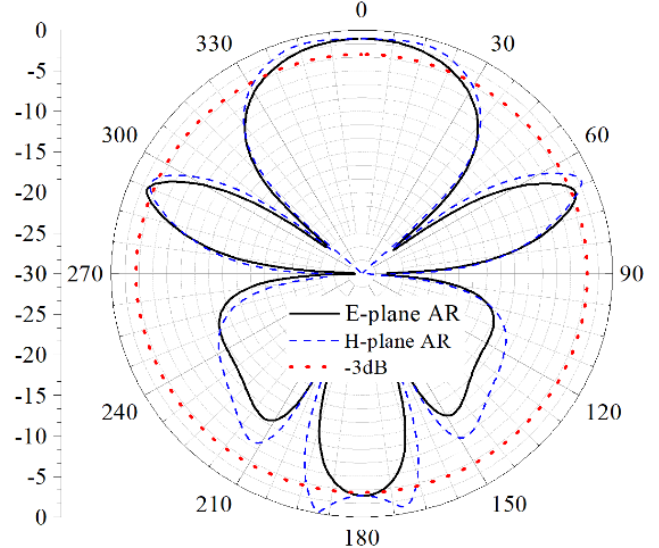

(b)

Figure 10. These figures are, (a) Radiation arrangement of $\mathrm{CP}$ antenna at $3.75 \mathrm{GHz}$ in E-plane and H-plane,

(b) Simulated AR in H-plane, E-plane of the CP antenna array at $3.75 \mathrm{GHz}$

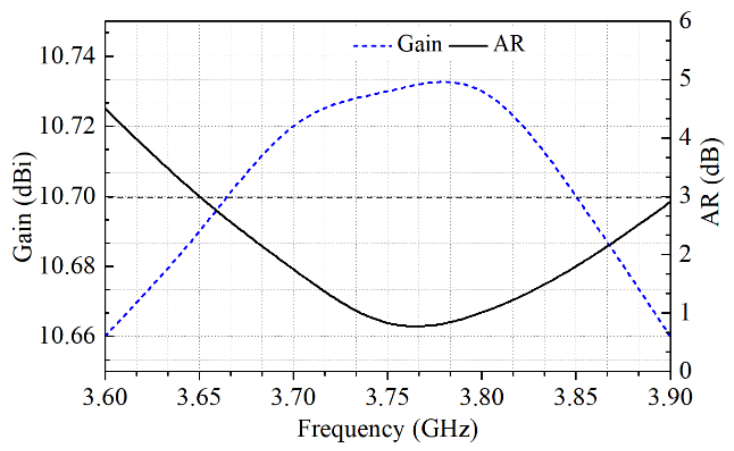

Figure 11. Simulated antenna array gain and axial ratio

Table 4. Comparison with related works

\begin{tabular}{cccccc}
\hline Ref & Freq $(\mathrm{GHz})$ & Gain peak $(\mathrm{dBi})$ & $\mathrm{BW}(\mathrm{MHz})$ & $\mathrm{BW}$ of CP $(\mathrm{GHz})$ & Antenna size $(\lambda)^{*}$ \\
\hline & & & & $1.4 \div 2.0$ & \\
{$[5]$} & 2.5 & 8.24 & 1200 & $2.1 \div 2.35$ & $1 \times 1 \times 0.39$ \\
& & & & $2.4 \div 2.6$ & \\
{$[6]$} & 1.56 & $\sim 4.8$ & 100 & $1.52 \div 1.56$ & $0.32 \times 0.32 \times 0.12$ \\
{$[16]$} & 1.6 & $\sim 5.5$ & 500 & $1.52 \div 1.65$ & $0.53 \times 0.53$ \\
{$[17]$} & 5.8 & 9.8 & 2800 & $5.5 \div 6.2$ & $0.9 \times 0.9 \times 0.38$ \\
This work & 3.75 & 10.73 & 1000 & $6.35 \div 6.8$ & $3.6 \div 4.93$ \\
\hline
\end{tabular}

\section{CONCLUSION}

The wideband CP antenna array with four printed dipole antenna elements is depicted in this paper. Our antenna array obtains the CP by applying the SR feeding approach based on the HC feeding network. The antenna bandwidth is $26.7 \%$ (at $-10 \mathrm{~dB}$ ), and the beam-width of circular polarization is $51^{\circ}$. The antenna achieves a peak gain up to $10.73 \mathrm{dBi}$. The centre frequency of $3.75 \mathrm{GHz}$, the antenna can be applied for $5 \mathrm{G}$ devices that prefer high gain and wideband $\mathrm{CP}$ antenna characteristics.

\section{REFERENCES}

[1] U. Singh, S. Biswas, K. Singh, B. K. Kanaujia, and C.-P. Li, "Beamforming Design for In-Band Full-Duplex MultiCell Multi-User MIMO LSA Cellular Networks," IEEE Access, vol. 8, pp. 222355-222370, 2020, doi: 10.1109/ACCESS.2020.3043264. 
[2] M. Ali, R. Dougal, G. Yang, and H.-S. Hwang, "Wideband (5-6 GHz WLAN band) circularly polarized patch antenna for wireless power sensors," vol. 2, pp. 34-37, 2003, doi: 10.1109/APS.2003.1219173.

[3] A. Khidre, K. F. Lee, F. Yang, and A. Eilherbeni, "Wideband Circularly Polarized E-Shaped Patch Antenna for Wireless Applications [Wireless Corner]," IEEE Antennas and Propagation Magazine, vol. 52, no. 5, pp. 219-229, Oct. 2010, doi: 10.1109/MAP.2010.5687547.

[4] C.-J. Wang, M.-H. Shih, and L.-T. Chen, "A Wideband Open-Slot Antenna with Dual-Band Circular Polarization," IEEE Antennas and Wireless Propagation Letters, vol. 14, pp. 1306-1309, 2015, doi: 10.1109/LAWP.2015.2403572.

[5] W.-S. Lee, K.-S. Oh, and J.-W. Yu, "A wideband circular polarized planar monopole antenna array with circular polarized and band-notched characteristics," Progress in Electromagnetics Research, vol. 128, pp. 381-398, 2012, doi: 10.2528/PIER12040307.

[6] X. Ye, M. He, P. Zhou, and H. Sun, "A Compact Single-Feed Circularly Polarized Microstrip Antenna with Symmetric and Wide-Beamwidth Radiation Pattern," International Journal of Antennas and Propagation, vol. 2013, pp. 1-7, 2013, doi: 10.1155/2013/106516.

[7] L. Zhang, Q. Luo, and S. Gao, "Wideband multilayer dual circularly-polarised antenna for array application," Electronics Letters, vol. 51, no. 25, pp. 2087-2089, Dec. 2015, doi: 10.1049/el.2015.3343.

[8] P. S. Hall, J. S. Dahele, and J. R. James, "Design principles of sequentially fed, wide bandwidth, circularly polarised microstrip antennas," IEEE Proceedings H Microwaves, Antennas and Propagation, vol. 136, no. 5, p. 381, 1989, doi: 10.1049/ip-h-2.1989.0069.

[9] D. Inserra, W. Hu, and G. Wen, "Design of a Microstrip Series Power Divider for Sequentially Rotated Nonuniform Antenna Array," International Journal of Antennas and Propagation, vol. 2017, pp. 1-8, 2017, doi: $10.1155 / 2017 / 9482979$

[10] Nasimuddin, Z. N. Chen, and K. P. Esselle, "Wideband circularly polarized microstrip antenna array using a new single feed network," Microwave and Optical Technology Letters, vol. 50, no. 7, pp. 1784-1789, Jul. 2008, doi: $10.1002 / \mathrm{mop} .23481$.

[11] J. Zhang, H. Yang, and D. Yang, "Design of a New High-Gain Circularly Polarized Antenna for Inmarsat Communications," IEEE Antennas and Wireless Propagation Letters, vol. 11, pp. 350-353, 2012, doi: 10.1109/LAWP.2012.2191382.

[12] S. X. Ta and I. Park, "Compact Wideband Circularly Polarized Patch Antenna Array Using Metasurface," IEEE Antennas and Wireless Propagation Letters, vol. 16, pp. 1932-1936, 2017, doi: 10.1109/LAWP.2017.2689161.

[13] T. Varum, J. N. Matos, P. Pinho, and R. Abreu, "Non-uniform broadband circularly polarized antenna array for vehicular communications," IEEE Transactions on Vehicular Technology, pp. 1-1, 2015, doi: 10.1109/TVT.2015.2500520.

[14] T. Tasuku and T. Nasato, "Wideband circularly polarised array antenna with sequential rotationsand phase shifts of elements," in ISAP, Tokyo, Japan, 1985, pp. 117-120.

[15] L. Baggen, S. Holzwarth, and W. Simon, "Phase array using the sequential rotation printed: analysis of coupling effects," Carl-Friedrich-Gauss-Str. 2, D-47475 Kamp-Lintfort, Germany, IMST GmbH.

[16] Y. Luo, Q.-X. Chu, and L. Zhu, "A Low-Profile Wide-Beamwidth Circularly-Polarized Antenna via Two Pairs of Parallel Dipoles in a Square Contour," IEEE Transactions on Antennas and Propagation, vol. 63, no. 3, pp. 931936, Mar. 2015, doi: 10.1109/TAP.2014.2387438.

[17] T. D. Bui, Q. C. Nguyen, and M. T. Le, "Novel wideband circularly polarized antenna for wireless applications," in Microwave Conference (APMC), 2017 IEEE Asia Pacific, Kuala Lumpur, Malaysia, Nov. 2017, pp. 430-433, doi: 10.1109/APMC.2017.8251472.

[18] C. Wang and Y. Ge, "A Novel Broadband Printed Dipole Antenna and Its Application for TD-LTE Communications," International Journal of Antennas and Propagation, vol. 2014, p. e960963, Sep. 2014, doi: $10.1155 / 2014 / 960963$.

[19] H. Jingjian, Z. Xiaofa, X. Shaoyi, W. Weiwei, and Y. Naichang, "Suppression of Cross-Polarization of the Microstrip Integrated Balun-Fed Printed Dipole Antenna," International Journal of Antennas and Propagation, vol. 2014, p. e765891, Apr. 2014, doi: 10.1155/2014/765891.

[20] M. Hamid and R. Hamid, "Equivalent circuit of dipole antenna of arbitrary length," IEEE Transactions on Antennas and Propagation, vol. 45, no. 11, pp. 1695-1696, Nov. 1997, doi: 10.1109/8.650083.

[21] K. V. Puglia, "Electromagnetic simulation of some common balun structures," IEEE Microwave Magazine, vol. 3, no. 3, pp. 56-61, Sep. 2002, doi: 10.1109/MMW.2002.1028363.

[22] W. Roberts, "A New Wide-Band Balun," Proceedings of the IRE, vol. 45, no. 12, pp. 1628-1631, 1957, doi: 10.1109/JRPROC.1957.278293.

[23] G. Kumar and K. P. Ray, "Broadband microstrip antennas," Boston, Mass: Artech House, 2003.

[24] J. Huang, "A technique for an array to generate circular polarization with linearly polarized elements," IEEE Transactions on Antennas and Propagation, vol. 34, no. 9, pp. 1113-1124, Sep. 1986, doi: 10.1109/TAP.1986.1143953.

[25] N. H. Nguyen, et al., "A Novel Wideband Circularly Polarized Antenna for RF Energy Harvesting in Wireless Sensor Nodes," International Journal of Antennas and Propagation, vol. 2018, pp. 1-9, 2018, doi: $10.1155 / 2018 / 1692018$. 


\section{BIOGRAPHIES OF AUTHORS}

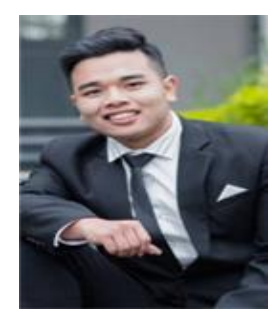

Tan Minh Cao received his Dipl. of Engineer (2020). He is a key member of Radio Frequency group (RF3i) at Department of Instrumentation and Industrial Informatics (3I), School of Electrical Engineering (SEE), Hanoi university of Science and Technology (HUST). His current interests include antenna design, high-frequency circuits, wireless communication, filter design, MIMO antenna, array antenna synthesis. He has experience in research on 5G systems antenna for base station and devices. Now he is working in Research \& Development Department (R\&D) at ACE antenna Company in Vietnam. His work is to design the antenna and filter for array antenna $4 \mathrm{G}$. He is also researching and developing for $5 \mathrm{G}$ systems.

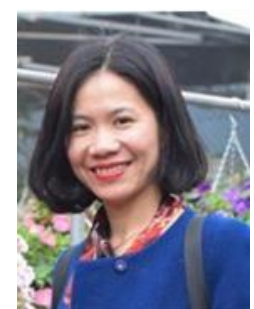

Thao Hoang Thi Phuong received the Dipl. of Engineer (2004), Master of Science (2007), and $\mathrm{PhD}$ degree (2019) in Electronics and Telecommunications from Hanoi University of Science and Technology, Vietnam. Currently, she is a lecturer at Electronics and Telecommunications Faculty, Electric Power University, Vietnam. Her research interests are antenna design, highfrequency circuits, metamaterials, wireless communication, and localization systems. She has had serveral publicattions in the ISI, Scopus jounals and international conferences in antenna and wireless communication field. She has a total experience of 15 years teaching and researching experience.

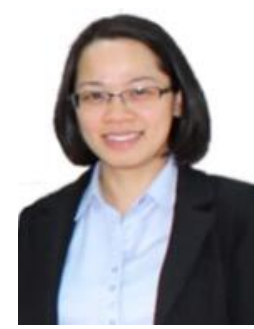

Thi Duyen Bui graduated in the field of Instrumentation and Industrial Informatics in 2004 and completed the master's degree in Control Engineering and Automation in 2007 at Hanoi University of Science and Technology. She is a PhD in Control and Automation Engineering, majoring in Measurement at Hanoi University of Science and Technology in 2020. Since 2005, Thi Duyen Bui is working as a lecturer at the Faculty of Automation Technology, Electric Power University. Her main research areas are antennas and high-frequency circuits, wireless communication, indoor localization system, metamaterials, and design of embedded systems for control and automation systems. 